\title{
REVISIONES
}

\section{El no-lugar de los sentidos: por un pensamiento crítico-situado en educación*}

The no-place of the senses: for a critical-located thinking in education

\section{O não-lugar dos sentidos: por um pensamento crítico-localizado em educação}

\author{
Luis Jaramillo $^{1}$, J. Carlos Aguirre ${ }^{2}$ \\ ${ }^{1}$ Doctor en Ciencias Humanas y Sociales - Educación. Universidad Tras-os-Montes (Portugal). \\ Profesor Universidad del Cauca. E-mail: ljaramillo@unicauca.edu.co \\ ${ }^{2}$ Magíster en Filosofía, Universidad de Caldas. Profesor Universidad del Cauca. \\ E-mail: jcaguirre@unicauca.edu.co
}

\begin{abstract}
RESUMEN
El escrito es una apuesta comprensiva por el no-lugar de los sentidos como eje de enunciación epistémica; allí, los sentidos participan como morada de vida para dar nombre a saberes que recrean al sujeto como un ser con pensamiento crítico-situado y a su vez de frontera; lugar que le permite vivir y sentir el territorio más allá de una externalidad positiva o pragmática y más acá de una interioridad sensual.
\end{abstract}

Palabras clave: territorio, lugar, sentidos, subjetividad.

\begin{abstract}
This paper offers an effort of understanding the no-place of the senses as the axis of the epistemological enunciation. There, the senses participate as the dwelling of life to give a name to the knowledge that recreates the individual as a being with a critical-located thinking. At the same time, it creates a border that allows him, for one side, to live and to feel the territory beyond of a positive or pragmatic externality, and for the other side, a sensuous interiority.
\end{abstract}

Key words: territory, place, senses, subjectivity.

\section{RESUMO}

O artigo é uma tentativa de interpretar o não-lugar dos sentidos como o eixo central da enunciação epistemológica. Neste lugar, os sentidos participam como a morada da vida para dar nome aos conhecimentos que recriam o sujeito como um ser com pensamento crítico-localizado. Ao mesmo tempo, este lugar cria uma fronteira que lhe permite tanto viver e sentir o território além de uma externalidade positiva ou pragmática, como uma interioridade sensual.

Palavras-chave: território, lugar, sentidos, subjetividade.

\footnotetext{
* El presente trabajo hace parte de las reflexiones adelantadas al interior del Grupo de investigación Fenomenología
} y Ciencia, inscrito en la Vicerrectoría de Investigaciones de la Universidad del Cauca, Colombia. 


\section{INTRODUCCION}

En un salón de clase una maestra explica la taxonomía de las plantas, su guía es la cartilla de Ciencias Sociales. En el procedimiento le dice tanto a niños como a niñas que ubiquen en dos columnas de sus cuadernos las plantas que son medicinales y las que son comestibles; o sea, que las ordenen en torno a su característica esencial: alimenticia o curativa. Como era de esperarse, los "ruidosos" estudiantes colocaron en la columna derecha diversidad de frutales y hortalizas; del mismo modo, llenaron la columna izquierda con el nombre de las plantas medicinales que la maestra-cartilla repetía a sus estudiantes. En medio de la actividad, una estudiante colocó una planta, la Caléndula, en la columna derecha, es decir, de los alimentos. Ante el supuesto error, la profesora increpa a la niña a observar bien, ya que la cartilla le indica que la Caléndula es medicinal y no un vegetal nutricional; la niña, un poco extrañada y con cierto temor, contesta a la maestra que con Caléndula su mamá le da color a la sopa del almuerzo y no es un "remedio" tal y como lo expone la cartilla ${ }^{1}$.

Esta historia parece hablarnos de una monocultura institucional que privilegia el texto frente a la experiencia; relata que aquello que llamamos conocimiento no necesariamente tiene como única vía de acceso un componente teórico-formal; por el contrario, se encuentra plagado de infinidad de vivencias en un mundo llamado vida; mundo al que se accede por multiplicidad de vías, entre ellas los sentidos, que nos permiten un contacto directo con nuestro ser corpóreo en tanto seres-en-el-mundo (Merleau-Ponty, 2000).

La planta herbácea llamada Caléndula, de flores amarillas o anaranjadas, es utilizada en su esencia botánica para usos ornamentales y medicinales; sin embargo, en la cotidianidad de las comunidades campesinas se convierte en una planta que da color a un potaje llamado "caldo". La estética en este tipo de alimentación proporciona un nuevo sentido a la taxonomía del reino vegetal, específicamente a este tipo de herbáceas. Esta aparente confusión de clases de una taxonomía nos recuerda la clásica mención que hace Foucault, en el prefacio a las Palabras y las Cosas (2001), de un cuento de Borges en el que se dividen enciclopédicamente los animales del siguiente modo:

a) pertenecientes al emperador, b) embalsamados, c) amaestrados, d) lechones, e) sirenas, f) fabulosos, g) perros sueltos, $h$ ) incluidos en esta clasificación, i) que se agitan como locos, j) innumerables, $k$ ) dibujados con un pincel finísimo de pelo de camello, l) etcétera... En el asombro de esta taxonomía, lo que se ve de golpe, lo que, por medio del apólogo se nos muestra como encanto exótico de otro pensamiento, es el límite del nuestro: la imposibilidad de pensar esto (2001: 1).

Parece imposible pensar, en nuestras lógicas occidentales, que las hojas anaranjadas o amarillas de la Caléndula puedan servir para algo más que ornamentación o ser terapéuticas para el dolor de estómago o para infecciones en la matriz. Su coloración puede aportar un nuevo sentido al interior de un almuerzo.

Esta experiencia se dio en el 2008, en el marco de las capacitaciones docentes que semestralmente el Departamento de Pedagogía de la Universidad del Cauca ofrece a los docentes de la Educación Básica y Media del Departamento del Cauca, en asocio con la Secretaría de Educación Departamental. 
Esta anécdota escolar nos impele a admitir que los sabores hacen parte de nuestros territorios; la gestación de la vida es consumida por la vida misma que nos acicala y nos envuelve culturalmente. Igual sucede con los aromas emanados de la misma naturaleza, los cuales se incorporan en una cultura para ser parte de una diversidad que trasciende la etnia y los límites fronterizos de las comunidades ${ }^{2}$. El olor, así como el sabor, son altamente emocionales, se olfatea la existencia como prueba de estar vivos; con el olor entran en escena elementos de nuestro ser cotidiano: los recuerdos, las creencias, las singularidades, la experiencia... lo acontecido (Jaramillo y Aguirre, 2008).

Acceder al conocimiento por la experiencia directa de nuestro cuerpo-vivido, a través de los sentidos, fue planteado por Husserl como un retorno al olvidado mundo de la vida; ese olvido fue el sello de las ciencias en la modernidad. Para Husserl, las ciencias dejaron de lado el conocimiento de un mundo dado precientíficamente en la experiencia sensible cotidiana de modo subjetivo relativo, desconociendo que "cada uno de nosotros tiene sus apariciones y para cada uno ellas valen como lo que efectivamente es" (Husserl, 2008: 65). Esto nos dice que la realidad se nos da por escorzos, apariciones de maneras diferentes, lo que implica entrar en diálogo constitutivo de los objetos y los seres a través de las distintas maneras como se presenta la realidad a la conciencia, sin llegar a negar por esto su singularidad. Por tanto, cualquier aproximación a la verdad es gracias a la intersubjetividad que vivimos en la Lebenswelt o Mundo de la Vida.

En los siguientes apartados se intentará hacer una breve exégesis -no agotada- de cómo la modernidad, a través de las ciencias fisicalistas, cayó en una especie de idealismo epistémico al tratar de soslayo -o simplemente desechar- la correlación hombre-mundo en el acto mismo del conocer. Seguidamente, y como posición contraria a lo anterior, se intentará hacer una crítica a cierto tipo de conocimiento sensualista, que tiene como fin último un sentido común ingenuo fundamentado en los meros sense data; esta última postura se afinca en un empirismo clásico que se mueve en la seguridad de experiencias perceptivas. Finalmente, se pretenderá demostrar cómo los sentidos tienen un sentido y esto gracias a un pensamiento crítico-situado que asume el Lugar como un contexto para la enunciación y el acontecimiento, lo que permite pensar el territorio más allá de un romanticismo pueril.

\section{LOS SENTIDOS: LUGARES DE SOSPECHA PARA EL MUNDO DE LA CIENCIA MODERNA}

La ciencia moderna tendría su irrupción en el Renacimiento tardío del siglo; en esta época, pese a que la Tierra dejó de ser el centro del universo, el hombre, con sus nuevos conocimientos, la herramienta matemática y los instrumentos emergentes, se consideró el centro del mundo y señor del universo. Esta posición le permitió reducir la naturaleza a objeto y la vida a utilidad y necesidad. Sería Bacon, y posteriormente Galileo, quienes cristalizarían un método exitoso a partir de las invariaciones y regularidades del mundo natural. La Ciencia, vista desde esta perspectiva, sería la encargada de estudiar

2 El sociólogo colombiano Orlando Fals Borda habla de cómo las comunidades del Amazonas en límites con el Brasil intercambian objetos, saberes y experiencias, lo cual les permite vivir más allá de los límites fronterizos de los países. 
nomológicamente la esencia de todo lo existente. En el plano filosófico, Descartes, a través de la duda metódica, introdujo la sospecha de lo conocido a través de los sentidos, pues estos son una puerta de engaño y error, obstáculos para el conocimiento apodíctico que garantiza universalidad y neutralidad valorativa a los objetos estudiados, incluyendo, por supuesto, los procesos de interacción y valoración de las comunidades.

Con una lógica racional abarcante, los sentidos fueron objeto de desconfianza y menosprecio para quienes pretendían una verdad absoluta; en términos baconianos, son ídolos que atan al sujeto al conocer instintivo y sinuoso, muy cercanos al dogmatismo y a la especulación. En tal sentido, todo aquello que se pudiera tocar, ver, oler, gustar o sentir, era material espurio frente al pensamiento determinista que se preguntaba por el cómo funcionan (física y mecánicamente) los objetos en el cosmos. Así, la modernidad, en términos kuhnianos, dio paso al paradigma de la simplicidad, denominado por Gaitán (2008) ideal o mentalista, que buscó, por la vía de la razón, la correspondencia ente los conceptos y sus objetos. Fue un paradigma que hizo clara escisión entre la mente y el cuerpo tras la búsqueda de un "pensamiento puro"; en él, se creyó lograr exactitud a través de las formas ideales como absolutos posibles gracias a un método a priori, sistemático y omniabarcador (Aguirre y Jaramillo, 2009).

Para la empresa epistémica moderna, las matemáticas y la geometría jugaron un papel importante: se convirtieron en fuente de exactitud que daba coherencia a los enunciados a través de los hechos; emerge así una secularización de la vida ligada al orden y a lo positivo; es decir, a lo útil y pragmático, se da apertura a una actitud tecnológica y a una matemática recuperada que, a decir de Mardones: "permitieron medir las propiedades de un fenómeno por su determinación métrica y numérica con un alto énfasis de abstracción e idealización de la ciencia" (1991: 25). Estos procedimientos científicos castraron la percepción y la relacionalidad de los fenómenos -dadas por la vía de los sentidos- del mundo de la vida de los nuevos científicos y, con ello, el modo intencional de proceder de artistas y artesanos de la época.

El éxito de Galileo y del posterior desarrollo de esta tradición radica en su habilidad para arrinconar diversas complicaciones empíricas, para trabajar conceptos ideales, como "el péndulo ideal", etc. Es decir, que junto a las fuerzas sociales indicadas, hay que poner a los hombres: los artistas-ingenieros del renacimiento, hombres geniales como Leonardo da Vinci que inician la vinculación sistemática del saber académico con la empírica artesanal. El mismo Galileo, durante su estancia como profesor de matemáticas en la Universidad Padua (15921610), tuvo numerosos contactos con artesanos para trabajar en su laboratorio y solucionar problemas físicos de las bombas de agua, artefactos militares, etc. (Mardones, 1991: 26).

La vida cotidiana de los artesanos fue permeada por los tiempos modernos de la matematización de la ciencia. Muchos artistas, en aras de alcanzar un estatus de cientificidad objetiva, rindieron sus percepciones e intuiciones al pensamiento mentalista, lugar donde ya no tendrían la necesidad de volver a establecer los modos de realización empírica; gracias a la novedad del método positivo, el pensamiento concreto fue cosa del pasado, catalogado como de orden inferior; lo preeminente, entonces, vendrá a ser la métrica causal y el grado supremo de objetividad reflejado en los fenómenos. Esta manera de proceder repercutió en la relación hombre-naturaleza al menos en tres aspectos, a saber: a) la sensibilidad se redujo al campo fisiológico, muy cercano al concepto de sensiblería; 
b) la subjetividad fue considerada superchería e emotividad subyacente de la razón; y c) la intuición será tan solo un chispazo alejado del acto racional.

Ahora bien, fue Husserl, entre otros, quien cuestionó esta actitud de la ciencia físicomatemática; consideró que ella no puede desconocer la relación del hombre con su mundo, lo que implica que no puede comprender al sujeto sin su relación con el mundo y al mundo sin su relación con el hombre; al interior de la subjetividad humana, el hombre es sujeto en el mundo, pero, a su vez, objeto del mismo; paradoja que le hace arte y parte de aquello que acontece tanto en su exterior como en su interior. Para Husserl (2008), toda elaboración científica descansa en un suelo predado llamado Mundo de la Vida, que es la experiencia sensible que viene dada siempre de antemano como evidencia incuestionable, y de toda vida mental que se alimenta de ella, tanto la acientífica como, finalmente, también la científica. Esta experiencia "sensible" no se reduce meramente a una sensibilidad fisiológica, sino que está cargada de significaciones volitivas, afectivas, valorativas y estéticas. Diríamos, entonces, que el Mundo de la Vida es el suelo primigenio donde el hombre constituye su realidad en hontanar de mundos posibles.

Toledo (2007), en correspondencia con Schutz, configura el Mundo de la Vida como arena de sentido sobre la cual se configuran otras realidades que pueden ser modificaciones suyas. Estas Realidades Múltiples forman parte de la vida cotidiana, tales como: el mundo de las fantasías, el mundo de los sueños y el mundo de la contemplación científica, entre otros. Por tanto, alejar de tajo el mundo de la vida, y con ello los sentidos como fuente originaria de conocimiento, no sólo fue un abuso de la ciencia moderna, sino también la castración de un sujeto pensante que pretendió llenar su cabeza de razón lógica-formal, muy cercana a la invención esquizoide que lo llevó al envanecimiento; hombre que pretendió estar alejado de una realidad sensible o sensitiva de la cual le es imposible abstraerse.

Volviendo a los sabores de una sopa, diríamos que el hombre en esta época moderna adobó y horneó saberes que poco a poco fue cocinando en conocimientos ${ }^{3}$; alimentos cargados de un alto contenido lógico-formal que posteriormente fueron servidos en la gran mesa de la Ciencia para ser consumidos por comensales llamados comunidades científicas. Estas degustaron una "deliciosa" comida racional que poco a poco se fue especializando con recetas de carácter ideal; tal cocción pasó, con el tiempo, a ser el modelo o paradigma que se siguió sirviendo en la mesa para alimentar a los científicos "normales" en el restaurante de la cientificidad (Jaramillo, 2006). Retomando nuestra historia primera, diríamos que a este caldo le faltó el color de la Caléndula.

Con lo anterior no se quiere desconocer el avance y aporte del mundo moderno a las sociedades actuales; sus posibilidades de agenciamiento en el progreso de teorías dieron como resultado el descubrimiento de un mundo que nos era oculto en su riqueza natural; el aprovechamiento de los recursos en beneficio del bien-estar humano son innegables hoy en día. Lo que se quiere señalar es el olvido que tuvo el hombre de la Ciencia de su sedimento nutricio y vital de un mundo que no le es ajeno. Abstraerse de él para examinarlo

3 Según Vasco (1996), los saberes son más difusos y no están tan claramente circunscritos como los conocimientos. Los conocimientos están más delimitados, más precisos, más concretos ya sea que estén ubicados en el cerebro de la persona, ya sea que lo estén en los libros y artículos científicos, sobre todo en aquellos donde hay información válida, contrastada y confiable. En la medida en que se verbaliza un saber, sea en forma oral o escrita, se vuelve conocimiento. 
implicó la creación de una cultura occidental que se constituye, "con frecuencia, bajo el nombre de hombre, un ser que, por un solo y único juego de razones, debe ser dominio positivo del saber y no puede ser objeto de la ciencia" (Foucault, 2001: 356). Pretender no estar implicado o coimplicado desde de la experiencia sensible y perceptiva en el mundo, es tanto como ser vasija de barro que guarda lo dado por el mundo y cuestiona permanentemente aquello de lo cual fue hecha: ¡tierra! Nuestra vida tiene lugar sobre un fondo de sentido con el que cada uno de nosotros contamos permanentemente sin hacerlo explícito, sin que esté expresado o fijado de alguna manera para nosotros (Herrera, 2009). ¿Tendrá entonces el hombre que retornar al mundo de los sentidos?, ¿son ellos en últimas la principal fuente de conocimiento?; siendo así, ¿estaremos abocados a los ídolos de la caverna, engañados eternamente por aquello que se nos comunica sensiblemente? En los apartados siguientes se intentará brindar una mirada crítica a estos aspectos.

\section{LOS SENTIDOS Y EL CONOCIMIENTO: UNA SENSIBILIDAD HECHA SENSUALISMO}

Hume (2007), en años posteriores a Galileo, consideró, al igual que otros pensadores considerados empiristas, que el conocimiento se producía en la mente humana a partir de las impresiones de los sentidos; la radicalidad de estas posturas lo llevó a un desafiante tipo de escepticismo que socavaba las propias bases de la ciencia. Los empiristas consideran que desde una impresión sensible se puede tener una idea. Así, el papel que miro mientras escribo es la impresión sensible y la imagen mental que tengo cuando cierro los ojos y trato de imaginarlo es la idea. Las impresiones sensibles pueden ser a su vez ser simples y complejas; por ejemplo: gustar una manzana es una impresión compleja, ya que la puedo percibir desde impresiones simples como textura, gusto, grados de color y olor. Según Hume, se puede conocer los objetos a través de sus cualidades expresadas en la sensibilidad, lo cual da como resultado un reforzamiento del sentido común pues posibilita un moverse entre las cosas de la vida cotidiana; esta relación entre impresiones sensibles e ideas es del tipo causa-efecto, pues una impresión simple siempre será anterior a la idea simple y ésta, a su vez, es anterior a cualquier idea compleja.

El empirismo llevó al hombre a ser un experimentador de lo percibido a través de los sentidos; sensualista que reflexiona poco sobre el objeto conocido, muy cercano al papel de receptor del conocimiento. En la relación sujeto-objeto, éste es tan solo un ente pasivo en tanto se limita a recoger las impresiones que el objeto le otorga (Schaff, 1974). Esta manera de conocer está más cercana a la lógica del científico moderno -quien determina las causas con el fin de explicar los efectos de los fenómenos- que a la de un sujeto crítico que coloca el mundo en cuestión. El empirismo, en este sentido, es el otro extremo del péndulo de las investigaciones positivas pues considera los sentidos como única vía de experimentación sobre los objetos percibidos y no una reflexión crítica que se conecta al mundo de manera corpórea.

Popper, al interior de la filosofía de la ciencia, consideró la teoría empirista como equívoca; para él, si bien los sentidos participan en un primer momento como acceso al conocimiento, la ciencia sólo progresa a partir de un pensamiento crítico. Aunque los sentidos nos acercan a la realidad, es errado considerar que "si cualquiera de nosotros desea conocer algo que aún desconoce sobre el mundo, no tiene más que abrir los ojos y 
mirar a su alrededor. Hemos de enderezar las orejas y prestar oídos a los ruidos" (Popper 1992: 65); esta actitud es conocida al interior de la historia de la epistemología como tabula rasa. Para Popper, los hechos que se presentan al sujeto por la vía de los sentidos son posteriormente procesados de manera reflexiva a fin de ser adoptados o rechazados desde una toma de posición; esta actitud crítica forma parte de nuestras facultades vitales y es comúnmente adoptada por el hombre de la ciencia (Aguirre y Jaramillo 2009). Ahora bien, es clara la intención del científico al pretender pasar de una actitud natural de los sentidos o sentido común ingenuo, a un sentido común ilustrado o actitud teórica; sin embargo, ¿qué sucede con los sentidos en la relación naturaleza-cultura? ${ }^{4}$ ¿Será posible admitir una visión sensualista (sentidos) como garante de un pensamiento situado?

Se han considerado dos visiones, por un lado, la sensibilidad hecha sensualismo en las doctrinas empiristas; por el otro, la denuncia popperiana a la supravaloración de los sense data y la apuesta por una actitud crítica. Apoyados en las propuestas del filósofo Emmanuel Levinas, intentaremos responder las preguntas que culminaron el párrafo anterior, las cuales no son más que la apertura a las posibilidades de un pensamiento crítico-situado.

Comencemos afirmando que en la relación del hombre con su mundo, Levinas critica una corriente de pensamiento moderno que nace en Alemania y que, en sus palabras, inunda los rincones paganos de nuestra alma occidental. Tal corriente existencial invita al hombre a volver a casa; o sea, recuperar su mundo a partir del retorno; para Heidegger y posteriores pensadores (heideggerianos), "los hombres lo habrían perdido [el mundo] y no conocerían más que la materia erigida frente a ellos, objetada, en cierto sentido, a su libertad. No conocerían más que objetos" (Levinas, 2004: 290). Pensamiento del regreso que intentó recuperar lo perdido de la casa, o lo no visto como extraño, debido a la obviedad del estar pegado materialmente al lugar; para ello, necesitaría reencontrarse con el mundo, recuperarlo, y así

Recuperar una infancia acurrucada misteriosamente en el Lugar, abrirse a la luz de los grandes paisajes, a la fascinación de la naturaleza, a la majestuosidad con la que se asientan las montañas; es seguir un sendero que serpentea por los campos; es sentir la unidad que instaura el puente que comunica las dos orillas del río y la arquitectura de los edificios, sentir la presencia del árbol, el claroscuro de los bosques, el misterio de las cosas, de un cántaro, de los zapatos gastados de una campesina, el destello de una jarra de vino sobre un mantel blanco. El Ser mismo de lo real se manifestaría detrás de estas experiencias privilegiadas, dándose y confiándose a la custodia del hombre. Y el hombre, guardián del Ser, obtendría de esta gracia su existencia y su verdad (Levinas, 2004: 290).

La filosofía heideggeriana es considerada por Darío Botero (2004) como una filosofía de la finitud y de la nada al reducir al hombre a su mínima expresión; para Botero, Heidegger "fue un espíritu atormentado, un provinciano enraizado profundamente en el sur de Alemania, en cuya geografía los fantasmas de la mística jugaron siempre, en distintas

4 Para Arturo Escobar (2000) no se pueden interpretar los mapas nativos (no modernos) de lo social y lo biológico en términos de los conceptos de nuestros conceptos de la naturaleza, la cultura y la sociedad. Para muchos grupos indígenas y rurales, la cultura no provee una cantidad particular de objetos con los cuales se pueda manipular la naturaleza... La naturaleza y la cultura deben ser analizadas, por ende, no como entes dados y presociales, sino como constructos culturales (p. 117). 
formas, un papel en su vida (...) para él, el mundo es un fenómeno de conocimiento, mientras que la tierra es un valor sensitivo intelectual" (108).

Esta doctrina del lugar es reconocida por Levinas como sutil y nueva, que se atrinchera al espacio como anunciación para ver de nuevo las cosas como reconocimiento de lo propio y lo no propio; crítica rimbombante que pone en cuestión todo aquello que no hace parte del lugar; posición de moda en la época actual en la que algunos círculos académicos consideran lo nativo como exótico y original, como exclusividad de lo étnico, llámese indígena, afrodescendiente o mestizo; discursos que ubican a estas comunidades con ciertos encantos de la tierra, un nuevo descubrir de la naturaleza en la que el hombre rural siempre ha estado en casa, unido a su terruño. Estas experiencias nos hacen ver al hombre como un pastor del rebaño o protector del medio ambiente; campesino cuidador de la tierra en la que descubre su "verdadera existencia" a través del mito de la naturaleza misma. En su verdad local, este hombre ya no necesitará de argumentos lógicos fundados en sistemas científicos, para él será suficiente habitar el lugar, el ser ahí: "para él, será suficiente caminar para apoderarse de todo, para apresar y hablar de lo apresado; todo está a su disposición, todo le pertenece con la aprehensión original del lugar, todo le es com-prendido" (Levinas 1977: 62).

Para Levinas, esta posición sensualista es presa de la finitud, de un ser que no mira más allá de sus narices, pues asume el retorno al lugar como ese privilegio "original" que le diferencia del extranjero, del foráneo que nada tiene que ver con él porque no pertenece a su comunidad; emerge, entonces, desde las mismas entrañas del lugar, un proceso de autoexclusión en el forcejeo de sentir al otro como invasor, en tanto no hace parte del clan al cual pertenezco; proceso autoexcluyente que desconoce al ser humano como alguien que es mucho más que las supersticiones del lugar, por tanto, hoy en día se es

hombre, mujer u homosexual, blanco, indígena o negro, budista, cristiano o musulmán. La identidad, que fuera durante los últimos dos siglos una dimensión del lazo social, amenaza hoy ese lazo desde la exacerbación individual e implosiva: sólo me siento yo desalojando al otro, rebajándolo, expulsándolo de mi mundo de pertenencia (Barbero, 2004: 35).

Esto ha originado que se privilegie al hombre del campo como sujeto ancestral, que posee ya no conocimientos sino saberes - no es gratuito el que la frase diálogo de saberes comienza a ser el cliché de nuestro tiempo-, posible trampa del saber que Santiago CastroGómez (2005) hace notar a través del excesivo interés de las grandes multinacionales farmacéuticas, por lo ancestral y lo milenario de carácter curativo.

Ahora bien, Levinas reconoce el valor de la tierra y la forma como nos acercamos a ella, en tanto es en sí misma fuente de valor y reflexión de la vida como una posibilidad para servir a los demás, para significar lo que somos en nuestra altura humana y poder concebir al Otro en su real alteridad, no exótico ni extraño, con una familiaridad de la casa, sino como absoluto-crítico con capacidad para reflexionar el lugar; un ser extraño que al habitar su espacio, salta de él para ser abrirse el Otro sin los roles tipificadores de una conciencia occidental abarcadora, que de manera invasora pretende decir "lo que es".

Contrario del volver a casa, lo que nos asiste es la metáfora de un no-lugar en nuestro propio lugar, de un pensamiento crítico-situado que nos hace vivir los sentidos fuera del 
exotismo y la tiranía del habitar campesino al ser catalogados como tardos en entendimiento o simpáticos y alegres por vivir en una realidad fantástica, mas no validados en los procesos reflexivos.

Volviendo a nuestra historia de la Caléndula, ésta dio color a la sopa no por haberse masticado cruda, o haber experimentado su color en el acto de ver; en el color de la sopa se vivió todo un proceso de preparación que involucró su cocción en un acontecimiento errático (su no-lugar) de ser concebida más allá de su ornamentación y su poder medicinal. Se evidencia aquí una serie de reflexiones validadas por las comunidades que le hacen vivir emancipadamente en su mismo habitar, "actitud fenomenológica en la que el hilo conductor del análisis intencional parte del objeto, pero remontando la corriente que lo constituye" (Levinas 1958: 91); la Caléndula deja de ser para ser al fin otra cosa, con sentido otorgado por la misma comunidad.

\section{EL SENTIDO CRITICO DE LOS SENTIDOS: POR UN PENSAMIENTO CRITICO-SITUADO}

Para Levinas, los sentidos tienen un sentido; es decir, no percibimos sólo fisiológicamente; somos más de lo que en el mundo se nos muestra; la realidad no se regala por deducción teórica ni se compila en volúmenes de textos que la describen, explican o comprenden. Los libros no nos aclaran la vida, es la vida la que nos aclara los libros; la manera como vivimos, como nos relacionamos, como experienciamos e interpretamos mundo. Realidad que es interpretada constantemente por nuestro ser-en-el-mundo en el cual vivimos de manera encarnada co-implicada.

Perceptivamente, nuestros sentidos captan una parte de la realidad, no la perciben de manera total, sino que actúan complementariamente gracias a cierta fe perceptiva ${ }^{5}$; podríamos decir que estos participan a partir de un mutuo entendimiento para dar a conocer al hombre cómo es el mundo, su mundo; cómo lo sienten y lo viven y lo adecuan a sus contextos. Más allá de la externalidad dada por el mundo mentalista promulgado en la Modernidad y del empirismo sensualista que percibe la realidad de manera ingenua, el cual empieza a ser objeto de tendencias posmodernas afincadas en el supuesto de verdades relativas a partir de la filosofía existencial del Lugar, lo que se propone es considerar el territorio desde la misma lógica-sensible de las comunidades a partir de un pensamiento-crítico-situado. Para ello, hemos de valorar fenomenológicamente los procesos constitutivos del sujeto en su relación con el mundo como son: la sensibilidad, la subjetividad y la singularidad; lugares donde los sentidos envuelven al sujeto para sentir críticamente su mundo como morada a partir de un no-lugar.

5 Para Merleau-Ponty (1970), la "Fe Perceptiva" es la que nos da la certeza de que "estamos ocupando el mundo con nuestro cuerpo, sin tener que elegir ni distinguir siquiera entre la seguridad de ver y ver lo verdadero, porque son fundamentalmente las mismas cosas"; en otras palabras, "tambalea la vieja sospecha de que todo me engaña y que el conocimiento de la realidad es inaccesible por los sentidos; el cuerpo siente el mundo que es y por tanto es preponderante su papel en la búsqueda de la verdad" (48). 


\subsection{LA SENSIBILIDAD}

Para Levinas, la sensibilidad consiste en su opacidad misma y en su espesor, una significación y una sabiduría propias, una especie de intencionalidad; ella no es, en ningún momento, la receptividad de una espontaneidad objetivante: "no aparece como pensamiento balbuciente destinado al error y a la ilusión, ni como trampolín del conocimiento racional" (Levinas, 1958: 94); para este autor, entonces, la sensibilidad no es un cajón vacío en el que se alojan las percepciones; en ella está implícito un sentido.

La sensibilidad, desde esta perspectiva, posibilita al hombre el dirigirse al mundo sin prejuicios científicos o con un fin sensualista; mediante la sensibilidad, éste, situado en un tiempo y un lugar, puede entretejer sentidamente el contenido de sensaciones que dan formas y significados a todo objeto que se ofrece al pensamiento. Perceptivamente se puede ver no sólo el objeto en su color; también es posible, sin tocarlo, sentir su textura, dureza y hasta olor. Aquí los sentidos participan más desde el cuerpo vivido que desde la funcionalidad de los sentidos. Merleau-Ponty (2000) al respecto diría que es la ciencia en su positividad la que nos ha enseñado a distinguir los sentidos por su función; pero que lo vivido en el cuerpo no se reencuentra a partir de datos; por el contrario, los mismos objetos se presentan de golpe como el centro de donde proceden para poder percibir de ello algo más que su función; así, se podrá ver lo aterciopelado, la suavidad y la dureza de los objetos desde su misma significación; es en esta perspectiva que los sentidos pasan a ser parte del mundo vivido y no de manera funcional como los ha utilizado la ciencia. Cortázar (2002), en el cuento Acefalia, expone que, a diferencia de los insectos que pueden regenerar ciertas partes de su cuerpo, nosotros podemos sentir diversamente.

\subsection{LA SUBJETIVIDAD}

Unida a la sensibilidad, la subjetividad permite romper todo pensamiento englobante y sensualista, al ser punto de partida de toda "receptividad (y, en este sentido, principio), hacia el aquí y el ahora a partir de los cuales todo se produce por primera vez" (Levinas, 1958: 98). Desde la intencionalidad de nuestros cuerpos-propios no nos ponemos en relación con los objetos sino en relación con nosotros mismos; o sea, nos movemos en el mundo como geómetras encarnados de una manera distinta a las corrientes empiristas, ya que no experimentamos por los sentidos para saber las causas de algo, sino que es nuestro propio cuerpo el que pasa a ser el punto cero de toda orientación desde el hecho mismo de situarnos en nuestros territorios.

Lo subjetividad, en este sentido, ya no es posible alojarla sólo al lado de las emociones como lo pretendieron en un tiempo ciertas corrientes psicológicas, ni menos como pensamiento amorfo o distorsionado de todo acto racional; la subjetividad sería más bien ese cuerpo-propio que se sale de corrientes mentalistas y empiristas para ser ella al fin y al cabo la protoimpresión "cuyo acontecimiento fundamental está en el hecho de tenerse; es decir, de tenerse a sí mismo como el cuerpo que se tiene sobre sus piernas" (Levinas, 1958: 95). El posicionamiento del lugar lo dirige hacia la toma de decisiones gracias a la protoimpresión recibida. Sería entonces la subjetividad-sensible el origen de nuestros pensamientos-situados al hacer que la "eternidad" de las ideas remita a un ser que piensa de manera encarnada, un sujeto situado temporalmente. Este pensamiento ya no pertenece exclusivamente al lugar sino a su ser corpóreo, haciéndole tomar posición 
y adoptar una actitud crítica frente a lo sentido perceptivamente. La apertura a una subjetividad sensible, contrario de lo que pudiera pensarse, le permite al sujeto procesar de manera re-flexiva la manera como vive y siente su mundo, lo cual quiere decir que la subjetividad está anclada a una razón crítica-situada a partir de la singularidad, tercer y último punto que se expone a continuación.

\subsection{LA SINGULARIDAD}

El ubicarnos temporalmente nos arranca de los tiempos absolutos de la historia universal. La singularidad nos habla de un sujeto indisoluble, no fragmentado; desde ella, el ser puede hablar por cuenta propia y no prestar sus labios para que otros hablen por él; contrario a la individualidad ${ }^{6}$, la singularidad une al sujeto a una comunidad en la cual cobran valor sus procesos constitutivos como: "la memoria, el recuerdo, el olvido, lo vivido; el sujeto nace en su historicidad y se reconoce en ella, sale del anonimato; ya no es objeto de mercancía ni esclavo de un tiempo que le prevé lo que será de su existencia" (Aguirre y Jaramillo, 2006: 61). Los lechos internos de la historia permiten al sujeto ser singular, crítico de su acontecer existenciario, habitante de un mundo que percibe por una sensibilidad irresistible que le hace acontecer de manera situada.

Esta posición nos remite a la investigación realizada por Erazo, Tumiña y Jaramillo $(2008)^{7}$, en la que se muestran los distintos usos que hacen los Guambianos de su medio natural a través del juego. En el estudio se comprendió que en la naturaleza los objetos no son objetos inertes o carentes de vida; por el contrario, son creación vital donde la naturaleza cobra sentido. En la investigación se encontró que los accidentes naturales que proporciona el territorio son posibilidades para que niños y niñas re-creen lugar; la misma naturaleza propició que los campos no se circunscriban a una cancha deportiva ni a un parque de "juegos" tal y como lo expresó un taita: "antes en los altos (lomas) casi no había campo de juego entonces así, donde hay cualquier espacio como limpio, entonces ahí es donde ponen a jugar" (FP/4-4: 1). En este sentido, el espacio no delimita el juego, es precisamente el juego el que recrea el territorio y lo construye como lugar-no lugar.

Para los Guambianos se juega cogiendo leña, se suben cuestas, se trae agua; trayectos propiciados por el oficio, donde el territorio es adaptado ya no a las necesidades de una tarea, sino a los infinitos deseos del jugar; para ellos "traer leña era como un juego. Cuando llevamos algo pesado es difícil pero era como juego, porque al lado nos encontrábamos con la naturaleza, por ejemplo, nos encontrábamos con los nidos de los pájaros y parábamos y jugábamos de que esto es nido esto lo de otro y así... entonces eso era feliz, pasábamos muy contentos cuando niño” (BM/2-2: 3).

6 En la modernidad el cuerpo fue aislable del hombre, sólo puede pensarse en las estructuras sociales de tipo individualista en las que los hombres están separados unos de otros, son relativamente autónomos en sus iniciativas y en sus valores. El cuerpo como un límite fronterizo que delimita, ante los otros, la presencia del sujeto, es factor de individualización (Le Breton, 2002).

7 Investigación denominada: "Los territorios del juego y los juegos del territorio", realizada en el resguardo indígena de Guambía (a cuyos habitantes se les denomina Guambianos), la cual pretendió comprender los diferentes juegos de los indígenas antes de que emergieran los deportes en la comunidad; en tal sentido, recurrimos a historias de vida de Taitas y Mamas. 
En este sentido, los territorios no sólo son fuente de producción y sustento comunitario, ni lugares para ser habitados y modificados culturalmente; ellos son campo de juego cuyos elementos constitutivos (lomas, ríos y árboles) pasan a ser "juguetes" y lo producido por esos elementos (frutos y miel) Las Delicias degustadas gracias a un juego saborizado.

En este estudio llamó la atención a los investigadores cómo los mismos juegos pueden dar nombre a un territorio por la actividad lúdica que allí se ejerce; un taita (AD) contó la historia de la vereda Las Delicias, la que lleva su nombre por la riqueza de los frutos que se producen: mora, carirrocio, uvillas, cerote y demás.

\begin{abstract}
...bueno, en esa hora en Las Delicias a lado de alli de Las Delicias habían cubillos, habían oca, habían cerotes, habían moras, todas esas moras cuando a nosotros nos mandaban a traer, cuando llegamos nos hicieron machacar en una batea grande y alli se raspaba la panela y se machacaba bien machacadito, acá los niños le daban una cucharadita pequeñita y al saborear le decían qué sentían, usted cómo lo siente, como le parece, es bueno o es un sabor diferente entonces es bien sabroso déme más, déme más, y desde allí se puso Las Delicias... En esa hora antes Las Delicias se decían Tre Wampik, Tre es sal y Wampik no habían cercos sino que todo es comunidad (AD/1-3: 3).
\end{abstract}

Antes la vereda poseía otro nombre Tre Wampik, pero fue precisamente la actividad de coger frutas la que originó el cambio de nombre. De este modo, fue la actividad jugada la que hizo que los sujetos pudieran nombrar a sus contextos; es decir, crear su mundo a partir de una practicidad-jugada. Lo anterior permitió comprender que "a diferencia de lo que tradicionalmente se cree: que el signo nos lleva a la significación, es la significación la que hace posible todo signo" (Aguirre y Jaramillo, 2006). Tre Wampik, ya no significa el sitio sin cercos donde el ganado bebe sal; ahora, a partir de lo encontrado en el propio territorio, se le denomina Las Delicias, y esto gracias a las diferentes posibilidades que la actividad propicia en la recolección y consumo de sus frutos, así como el poder llevarlos a casa para su preparación.

Por tanto, la vereda es nombrada por un pensamiento situado que asigna otro significado a lo encontrado, pues el fruto coge sabor con el juego, ambos -juego y fruto- se machacan en una batea y se les raspa panela para ser probados y contagiados de "Las Delicias" que brinda la tierra. Significación que responde a procesos propios de un interaccionismo simbólico, en tanto los actores sociales atribuyen sentidos a su mundo, a sus relaciones interpersonales y a sí mismos a través de acción social que ejercen y al sentido común crítico de ver y sentir su contexto: "En esos tiempos uno recolectaba muchas frutas como es la mora, los arrayanes y comíamos de esto en el campo abierto y también se llevaba para la casa y lo preparaban, todo es la actividad de la familia es reflejado en el juego" (ST/7: 15-2).

Es en familia que se aprueba, prueba y disfruta del fruto que se coge; es en la acción-jugada que se invita a dis-frutar con otros, a probar sabores; se crean juegos que comprometen los sentidos de los sentidos, ya que no sólo se juega a cosechar los frutos que se consumen en el acto, también se juega cuando estos se llevan para la casa y se preparan gracias a una mezcla que integra sentidos y sabores y que dan como resultado un producto matizado por el juego. 


\section{CONCLUSION}

Volviendo a nuestra primera historia de la Caléndula, en el no-lugar de los sentidos, ésta dejó de ser color ornamental y fuente medicinal para volverse dadora de sabor y textura hecha agua; ella salta de la columna izquierda del cuaderno de una niña, para situarse en el no-lugar de la sensibilidad, en las palpitaciones del cuerpo-propio; es decir, en el tacto de los ojos, lo humeante de la nariz y la salivación del gusto. En su no-lugar sentido hubo espacio para un pensamiento crítico situado, pues tuvieron que participar de manera patente: una sensibilidad propia, una subjetividad hecha piel y la singularidad propia de un tiempo interno. En la coloración de la sopa, la mamá de la niña, al colocar las flores de esta planta al caldo, tuvo que probarla primero para saber que no estaba intoxicando a su hija. En el no-lugar de los sentidos entonces, se pasa permanentemente de una actitud natural o ingenua, a un sentido común crítico que nos hace pensar encarnadamente que sentimos, fenomenológicamente hablando, más allá de nuestras impresiones ideales y sensibles, lo cual nos hace críticos de nuestro ser y acontecer inmediato.

\section{REFERENCIAS BIBLIOGRAFICAS}

Aguirre, J. y Jaramillo, L. (2009). La ciencia y el sentido común. Documento de trabajo surgido al interior del grupo Fenomenología y Ciencia. Popayán: Universidad del Cauca.

Aguirre, J. y Jaramillo, L. (2006). El otro en Levinas: una salida a la encrucijada sujeto-objeto y su pertinencia en las Ciencias Sociales. Revista Latinoamericana de Ciencias Sociales en Niñez y Juventud 4 ( $\mathrm{N}^{\circ}$ 2): 47-72.

Barbero, J. (2004). Crisis de Identitarias y transformaciones de la subjetividad. En: Debates sobre el sujeto. Perspectivas contemporáneas. Siglo del Hombre. Bogotá, pp. 33-45.

Botero, D. (2004). Martin Heidegger: La filosofía del regreso a casa. Buena Semilla. Bogotá.

Castro-Gómez, S. (2005). La poscolonialidad explicada a los niños. Universidad del Cauca / Instituto Pensar. Popayán.

Cortázar, J. (2002). Historia de Cronopios y de Famas. Suma de Letras. Madrid.

Erazo, E.; Tumiña, E. y Jaramillo, L. (2008). Los territorios del juego y los juegos el territorio. Trabajo de Grado. Programa de Educación Física. Facultad de Ciencias Naturales, Exactas y de la Educación. Universidad del Cauca.

Escobar, A. (2000). El lugar de la naturaleza y la naturaleza del lugar: ¿Globalización o Postdesarrollo? En: Lander, E. (comp.), La colonialidad del saber: eurocentrismo y ciencias sociales en perspectivas latinoamericanas. CLACSO. Buenos Aires, pp. 113-143.

Foucault, M. (2001). Las palabras y las cosas. Siglo XXI. Buenos Aires.

Gaitán, C. (2008). Sentido de la epistemología en las Ciencias Sociales. Conferencia orientada en el Primer Encuentro Nacional de Historia de la Educación Física, la Recreación, el Deporte y la Motricidad Humana. Facultad de Ciencias Naturales, Exactas y de la Educación, Universidad del Cauca, Popayán, diciembre 11-13.

Herrera, D. (2009). Husserl y el mundo de la vida. Anuario Colombiano de Fenomenología 4 (en prensa).

Hume, D. (2007). An Enquiry concerning Human Understanding, and Others Writings. Cambridge University Press. Cambridge.

Husserl, E. (2008). Crisis de las ciencias europeas y la fenomenología trascendental. Prometeo Libros. Buenos Aires. 
Jaramillo, L. y Aguirre, J. (2008). Educación y Mundo de la Vida. Revista U.D.C.A. Actualidad \& Divulgación Científica 11 ( $\mathrm{N}^{\circ}$ 2): 61-70.

Jaramillo, L. (2006). La ciencia de la motricidad humana. Paradigma o paradogma emergente de la educación física. Revista Motricidad y Persona 1: 17-24.

Le Breton, D. (2002). Antropología del Cuerpo y Modernidad. Nueva Visión. Buenos Aires.

Levinas, E. (2004). Heidegger, Gagarin y Nosotros. En: Difícil Libertad. Caparrós. Madrid, pp. 289-292.

Levinas, E. (1977). Totalidad e Infinito: ensayo sobre la exterioridad. Sígueme. Salamanca.

Levinas, E. (1958). Reflexiones sobre la "técnica fenomenológica". En: Husserl: Tercer coloquio filosófico de Royaumont. Paidós. Buenos Aires.

Mardones, J. (1991). Filosofía de las ciencias humanas y sociales; materiales para una fundamentación científica. Anthropos. Barcelona.

Merleau-Ponty, M. (2000). Sentido y sinsentido. Península. Barcelona.

Merleau-Ponty, M. (1970). Lo visible y lo invisible; seguido de notas de trabajo. Seix Barral. Barcelona.

Popper, K. (1992). Conocimiento objetivo: un enfoque evolucionista. Paidós. Barcelona.

Schaff, A. (1974). Historia y Verdad. Grijalbo. México.

Toledo, U. (2007). Realidades Múltiples y mundos sociales; introducción a la sociofenomenología [en línea] Cinta de Moebio: Revista Electrónica de Epistemología de Ciencias Sociales 30. Disponible en: www.moebio.uchile.cl/30/toledo.html

Vasco, C. (1996). Distintas formas de producir conocimiento en la educación popular. Revista La Piragua, 1: 10-33. 
Las colaboraciones, suscripciones y correspondencia deben ser dirigidas a la Dirección de la revista: Oficina de Publicaciones, Facultad de Filosofía y Humanidades, Universidad Austral de Chile, Casilla 567, Fono/Fax: 5663 221275, Valdivia, Chile. E-mail: eped@uach.cl

Las suscripciones incluyen los gastos de envío:

Chile: cheque o vale vista por \$10.000. Otros países: US\$ 15 .

El canje debe ser enviado a Biblioteca Central, Universidad Austral de Chile,

Correo 2, Valdivia 

ANDROS IMPRESORES

www.androsimpresores.cl 
